\title{
Relationship between auditory P300 amplitude and age of onset of schizophrenia in older patients ${ }^{1}$
}

\author{
John M. Olichney ${ }^{\mathrm{a}, \mathrm{d}, *}$, Vicente J. Iragui ${ }^{\mathrm{a}, \mathrm{d}}$, Marta Kutas ${ }^{\mathrm{a}, \mathrm{c}}$, Ralph Nowacki ${ }^{\mathrm{a}}$, \\ Shaunna Morris ${ }^{\mathrm{b}}$, Dilip V. Jeste ${ }^{\mathrm{a}, \mathrm{b}, \mathrm{e}}$ \\ ${ }^{a}$ Department of Neurosciences, University of California, San Diego, La Jolla, CA, USA \\ ${ }^{\mathrm{b}}$ Department of Psychiatry, University of California, San Diego, La Jolla, CA, USA \\ ${ }^{\mathrm{c}}$ Department of Cognitive Sciences, University of California, San Diego, La Jolla, CA, USA \\ ${ }^{\mathrm{d}}$ Neurology Service, San Diego Veterans Affairs Medical Center, 3350 La Jolla Village Drive, San Diego, CA 92161, USA \\ ${ }^{\mathrm{e}}$ Psychiatry Service, San Diego Veterans Affairs Medical Center, San Diego, CA, USA
}

Received 13 November 1997; received in revised form 9 April 1998; accepted 10 April 1998

\begin{abstract}
Auditory P300 amplitude reductions are well-established in young adults with schizophrenia. Little is known, however, regarding the P300 in older schizophrenia patients, especially those with late onset. We studied 28 middle-aged and elderly (mean age $=62.7$ years) patients $[14$ with early onset schizophrenia (EOS) and 14 with late onset schizophrenia (LOS)] and 14 normal comparison (NC) participants using an auditory oddball paradigm. Event-related potentials were recorded from 15 scalp electrodes and six non-scalp sites. There were no significant differences between EOS and LOS groups in neuroleptic dosage, symptom severity, reaction times, target-detection accuracy, or N100 and N200 ERP measures. The EOS, but not the LOS, group had significantly smaller auditory oddball P300 amplitudes than the NC group. Twelve of the 14 LOS patients had P300 amplitudes in the normal range. Smaller P300 amplitudes were associated with earlier age of onset $(r=0.48)$, longer duration of illness $(r=-0.49)$ and more severe alogia $(r=-0.50)$. We conclude that P300 abnormalities in schizophrenia may be a marker for a disease subtype with early onset and more severe information-processing deficits. (c) 1998 Elsevier Science Ireland Ltd. All rights reserved.
\end{abstract}

Keywords: Event-related potentials; Aging; Psychophysiology; Psychosis; Learning; Attention

\footnotetext{
${ }^{1}$ This work was presented, in part, at the 1996 annual meeting (November, 1996) of the Society for Neuroscience in Washington DC, USA.

* Corresponding author. Department of Neurology (9127), San Diego Veterans Affairs Medical Center, 3350 La Jolla Village Drive, San Diego, CA 92161, USA. Tel.: +1 619 5528585, ext. 3685; fax: +1 6195527513.
} 


\section{Introduction}

The P300 component of the event-related potential (ERP) is a late positive waveform that is typically maximal at centro-parietal midline sites $300 \mathrm{~ms}$ post-stimulus in simple categorization tasks. The P300 is best elicited by unexpected task-relevant events and is sensitive to manipulations of stimulus probability and task difficulty (e.g. Duncan-Johnson and Donchin, 1977; Donchin et al., 1986; Johnson, 1988). Due to its dependence on expectancy (subjective probability) and the allocation of capacity-limited attentional resources, the $\mathrm{P} 300$ has been proposed to reflect 'updating' of working memory (Donchin et al., 1986; Donchin and Coles, 1988). Its amplitude for events in the primary task has been shown to index the amount of perceptual resources used in dual task paradigms (e.g. Isreal et al., 1980; Kramer et al., 1983; Trestman et al., 1996).

Much evidence implicates multiple generators of scalp-recorded P300 activity, with contributions from the hippocampus, parahippocampal gyrus, temporoparietal junction, thalamus and frontal cortex (Knight et al., 1989; McCarthy et al., 1989; Smith et al., 1990; Kropotov and Ponomatrev, 1991). Abnormalities of all these structures have been reported in schizophrenia, although their relative importance remains controversial (Chua and McKenna, 1995).

P300 amplitude has been reported by numerous investigators to be reduced in young schizophrenia patients [for review see Ford et al. (1992)], but has yet to be characterized in older patients, particularly in those with later onset of illness. Prior work in younger schizophrenia patients has related the degree of P300 amplitude reduction to severity of psychopathology, primarily to positive symptoms in some studies (McCarley et al., 1993; Egan et al., 1994) but to negative symptoms in others (Pfefferbaum et al., 1989; Strik et al., 1993). Nonetheless, a reduced amplitude P300 in the auditory modality has been offered as a sensitive marker for the 'schizophrenia trait' due to several converging lines of evidence. First, auditory P300 amplitude reductions seem relatively insensitive to changes in clinical status (Duncan et al., 1987; Ford et al.,
1994). Second, abnormalities of both $P 300$ amplitude and latency have been observed in many 'unaffected' relatives of schizophrenia patients (Blackwood et al., 1991; Kidogami et al., 1992). Third, longitudinal studies of neuroleptic-naive patients have shown no significant change in the P300 after the initiation of neuroleptic treatment (Ford et al., 1994). In contrast, visual P300s may be more sensitive to changes in the clinical 'state' of schizophrenia patients (Duncan et al., 1987). Abnormalities of the auditory N100 (Roth et al., 1981; Baribeau-Braun et al., 1983; Frangou et al., 1997) and N200 (Anderson et al., 1995; Frangou et al., 1997) potentials in schizophrenia have been reported, albeit less consistently (Egan et al., 1994; Stefánsson and Jónsdóttir, 1996).

The Clinical Research Center (CRC) on latelife psychosis at U.C. San Diego has been following a cohort of older schizophrenia patients, some of whom have late onset of illness. These late onset schizophrenia (LOS) patients are of great theoretical interest in that they may represent a separate disease or diseases or, alternatively, they may properly belong within the 'schizophrenia spectrum' (Harris and Jeste, 1988; Murray et al., 1992). Recently, we reported LOS to have quite similar neuropsychological profiles to EOS, with a few exceptions (Heaton et al., 1994; Jeste et al., 1995). Specifically, LOS patients had less severe impairment in learning/acquisition and in abstraction/cognitive flexibility (Heaton et al., 1994; Paulsen et al., 1995; Jeste et al., 1997). Also, measures of attentional abilities (e.g. Digit Span forwards and backwards, Speech Sounds Perception Test) showed a slight tendency for greater impairment in EOS than in LOS (Heaton et al., 1994).

In this study, we sought to characterize the P300 in patients with LOS and to compare their responses with those of age-comparable patients with early onset schizophrenia (EOS). We hypothesized that $\mathrm{P} 300$ abnormalities (i.e. reduced amplitude and delayed latencies) would be more pronounced in patients with EOS than in LOS patients, due to somewhat greater deficits of learning/acquisition (processes which are largely dependent on working memory 'updating') and attention in EOS. In addition, we postulated that 
P300 amplitude would correlate positively with age of onset of schizophrenia (treated as a continuous variable), and inversely with severity of psychopathology and global cognitive impairment.

\section{Methods}

\subsection{Subjects}

We studied 28 middle-aged and elderly schizophrenia patients (14 with EOS and 14 with LOS) and 14 normal comparison (NC) subjects. All the EOS and LOS subjects met DSM-III-R criteria for a diagnosis of schizophrenia, with the exception of three subjects diagnosed with schizoaffective disorder (two of whom had a 'late onset' of illness after age 45). The EOS, LOS and NC groups were carefully selected to be comparable with respect to age, gender, handedness, ethnicity (predominantly Caucasian) and level of ed- ucation (Table 1). Per DSM-III-R, onset of prodromal symptoms at or after age 45 was used to define the LOS group, and onset of symptoms prior to age 45 defined the EOS group. All subjects underwent an extensive clinical assessment in our CRC, generally within 30 days of the ERP recording. This included the Brief Psychiatric Rating Scale (BPRS) (Overall and Gorham, 1962), the Scales for the Assessment of Positive and Negative Symptoms (SAPS and SANS) (Andreasen, 1982, 1984; Andreasen and Olsen, 1982), and the Mini-Mental State Examination (MMSE) (Folstein et al., 1975). All clinical diagnoses were based on the Structured Clinical Interview for DSM-III-R (SCID) (Spitzer et al., 1988) given by well-trained geriatric psychiatry fellows, and were confirmed by at least two board-certified psychiatrists at the research staffing. Participants were instructed not to take any CNS-active medications (e.g. neuroleptics, anticholinergics) on the

Table 1

Demographic and clinical characteristics of the three subject groups

\begin{tabular}{|c|c|c|c|c|c|}
\hline & $\begin{array}{l}\mathrm{NC} \\
(n=14)\end{array}$ & $\begin{array}{l}\text { EOS } \\
(n=14)\end{array}$ & $\begin{array}{l}\text { LOS } \\
(n=14)\end{array}$ & $P$-value $^{\mathrm{a}}$ & $\begin{array}{l}\text { Group } \\
\text { differences }\end{array}$ \\
\hline Age (years) & $63.1(8.6)$ & $62.8(7.5)$ & $62.5(8.4)$ & 0.98 & \\
\hline Education (years) & $13.2(1.7)$ & $12.7(3.3)$ & $13.0(3.6)$ & 0.91 & \\
\hline Gender (M:F) & $10: 4$ & $10: 4$ & $10: 4$ & & \\
\hline Number right-handed & 13 & 13 & 13 & & \\
\hline $\begin{array}{l}\text { Age of onset of } \\
\text { illness (years) }\end{array}$ & - & $27.9(8.4)$ & $54.6(7.6)$ & $<0.0001$ & EOS $<$ LOS \\
\hline Duration of illness $* *$ & - & $34.8(10.3)$ & $7.9(6.7)$ & $<0.0001$ & LOS $<$ EOS \\
\hline $\begin{array}{l}\text { Neuroleptic dose } \\
\text { (mg CPZE daily) }\end{array}$ & - & $521 \quad(918)$ & 149 (228) & $0.10^{\mathrm{a}}$ & \\
\hline MMSE total* & $28.9(1.0)$ & $26.1(2.6)$ & $28.2(3.0)$ & 0.009 & EOS $<$ LOS,NC \\
\hline BPRS total* & $22.4(4.9)$ & $31.9(8.4)$ & $32.8(9.6)$ & 0.002 & $\mathrm{NC}<\mathrm{EOS}, \mathrm{LOS}$ \\
\hline SAPS score** & $1.5(1.8)$ & $5.5(3.8)$ & $7.3(4.6)$ & 0.0001 & $\mathrm{NC}<\mathrm{EOS}, \mathrm{LOS}$ \\
\hline SANS score ${ }^{* *}$ & $1.7(2.1)$ & $8.9(3.3)$ & $8.1(4.0)$ & $<0.0001$ & $\mathrm{NC}<\mathrm{EOS}, \mathrm{LOS}$ \\
\hline Affective flattening & - & $1.9(1.4)$ & $1.8(1.0)$ & 0.77 & \\
\hline Alogia & - & $1.8(1.0)$ & $1.2(1.3)$ & 0.20 & \\
\hline Avolition/Apathy & - & $1.4(1.2)$ & $1.5(1.6)$ & 0.79 & \\
\hline Anhedonia/Associality & - & $2.0(1.3)$ & $2.4(1.4)$ & 0.41 & \\
\hline Attention & - & $1.8(1.0)$ & $1.2(1.1)$ & 0.16 & \\
\hline
\end{tabular}

${ }^{a} P$-values are for one-way ANOVAs comparing all relevant groups, except for neuroleptic dose where Mann-Whitney $U$-test was used to compare EOS and LOS.

${ }^{*} P<0.05 ; * * P<0.001$ (ANOVA).

Note. Values for continuous variables represent means (with S.D.).

Abbreviations. NC, normal comparison group; EOS, early onset schizophrenia; LOS, late onset schizophrenia; BPRS, Brief Psychiatric Rating Scale; SAPS, Scale for the Assessment of Positive Symptoms; SANS, Scale for the Assessment of Negative Symptoms; MMSE, Mini-Mental State Examination. 
day of the event-related potential (ERP) testing, prior to the recordings. Eighteen patients were on stable neuroleptic dosages, while seven patients (two EOS and five LOS) were not on any neuroleptic treatment for 30 days or longer prior to the ERP testing. Participants with a history of a major neurological disease (e.g. stroke, brain tumor, epilepsy), or current serious medical illnesses, or who fulfilled DSM-III-R (American Psychiatric Association, 1987) criteria for current alcohol or other substance abuse or dependence were excluded.

\section{2. $P 300$ paradigm}

After informed consent was obtained, participants were fitted with an electrode cap and seated in a comfortable chair. The P300 'auditory oddball' paradigm consisted of at least 400 tones. Seventy-five percent of trials were 'non-target' (or 'standard') tones and $25 \%$ were 'target' tones. The tones were presented at $50 \mathrm{~dB}$ above hearing threshold, and had a 200-ms duration, with interstimulus intervals varying from 1.0 to $1.5 \mathrm{~s}$, in a pseudorandomized series. Participants were instructed to press a button (counterbalanced between hands for each subject) in response to each 'target' tone (counterbalanced between 113 $\mathrm{Hz}$ and $200 \mathrm{~Hz}$ tones for each subject, so that approx. $50 \%$ of all trials, targets or standards, were composed of low tones and $50 \%$ of high tones). ERPs were synchronized to the onset of the tones. Reaction time and accuracy data were collected. Target tones were considered correctly detected when a button press occurred within $1200 \mathrm{~ms}$ of stimulus onset.

\subsection{Electrophysiologic recording techniques}

The electroencephalogram (EEG) was recorded from 21 sites (15 scalp sites, four electro-oculogram (EOG) sites, and bilateral mastoid sites) using an elastic electrode cap (Electro-Cap International) with embedded tin disk electrodes. All scalp channels were referenced off-line to the left mastoid on-line and were subsequently re-referenced to the average of the left and right mastoid recordings. The scalp electrode sites were from the following locations of the International 10-20 System (Jasper, 1958): Fz, Cz, Pz, F7, F8, T5, T6, $\mathrm{O} 1$ and O2. Additionally, we used scalp electrodes which approximate Broca's area and its contralateral homolog placed half the distance between F7 and T3 [BL, equivalent to FT7 in the extended 10-20 nomenclature (American EEG Society, 1991)], or F8 and T4 (BR, equivalent to FT8), Brodmann area 41 placed $33 \%$ of the interaural distance lateral to the vertex $(41 \mathrm{~L}, 41 \mathrm{R}$, these are approx. $1 \mathrm{~cm}$ lateral to $\mathrm{C} 5$ and $\mathrm{C6}$ ), and Wernicke's area and its contralateral homolog placed $30 \%$ of the interaural distance lateral to $\mathrm{Cz}$ and $12.5 \%$ of the nasion-inion distance posterior to $\mathrm{Cz}(\mathrm{WL}, \mathrm{WR}$, these are approx. $1 \mathrm{~cm}$ posterior to CP5 and CP6). Vertical and horizontal eye movements were monitored by electrooculography, using electrodes directly beneath and lateral to each eye. The EEG and EOG were amplified by Biotop 6R12 amplifiers with a bandpass ( $-12 \mathrm{~dB}$ filters) of $0.016-100 \mathrm{~Hz}$. The amplified signals were digitized on-line at a sampling rate of $250 \mathrm{~Hz}$ for a sampling epoch of $1024 \mathrm{~ms}$ duration (100 ms pre-stimulus and $924 \mathrm{~ms}$ poststimulus). The mean voltage during the $100 \mathrm{~ms}$ pre-stimulus epoch was defined as 'baseline' (i.e. $0.0 \mu \mathrm{V})$. Trials contaminated with eye blinks or movements, excessive muscle activity, or amplifier blocking were rejected by a computer algorithm prior to averaging (Iragui et al., 1993). Approximately $20 \%$ of the trials overall were rejected due to artifacts. There was a nearly identical number of accepted trials for each of the three groups [e.g. for target tones, the mean number of accepted trials $( \pm$ S.D.) was $90 \pm 8$ for NC, $87 \pm 29$ for EOS, $90 \pm 24$ for LOS; $P=0.93$ ]. This was accomplished by presenting additional stimuli at the time of the recording to those participants who exhibited frequent blinking or had other persistent EEG-artifacts.

\subsection{ERP measures}

For each subject, separate ERP averages were calculated for target and non-target tones (collapsed across tone frequency and responding hand 
for this analysis). ERP amplitudes and latencies were quantified by computer algorithms as follows:

\subsection{1. $P 300$}

Mean amplitude of the P300 (i.e. the P3b) was measured between 350 and $450 \mathrm{~ms}$. The P300 peak amplitude was defined as the amplitude of the most positive peak between 300 and $550 \mathrm{~ms}$ post-stimulus onset: the P300 latency (or peak latency) was the latency at which this peak occurred. P300 amplitude was measured at all 15 scalp channels (i.e. Fz, Cz, Pz, F7, F8, BL, BR, 41L, 41R, T5, T6, WL, WR, O1, O2).

For individual subject and correlational analyses, P300 measurements were taken from Pz. Before the selection of individual peak amplitudes and latencies for all ERP components, the waveforms were subjected to digital low-pass filtering using a $15-\mathrm{Hz}$ cutoff, to reduce highfrequency perturbations. An abnormality of the P300 amplitude was defined as any value poorer than 1.5 S.D. from the mean of the NC group, at Pz.

\subsection{2. $N 100$}

The N100 was measured at all 15 scalp channels. N100 amplitude was defined as the most negative peak between 90 and $160 \mathrm{~ms}$ post-stimulus onset. N100 latency was defined as the time point at which this peak occurred.

\subsection{3. $N 200$}

The N200 amplitude was defined as the most negative peak between 210 and $310 \mathrm{~ms}$ poststimulus onset and measured at all 15 scalp channels. N200 latency was defined as the time point at which this peak occurred.

\subsection{Statistical analyses}

Two-way split-plot analyses of variance (ANOVAs) were conducted for the mean amplitudes, peak amplitudes, and peak latencies of the P300 waveform with subject group (EOS, LOS, NC) and electrode site (repeated measures across all 15 scalp sites) as factors. To adjust for violations of the assumption of sphericity, the Greenhouse-Geisser correction procedure (Greenhouse and Geisser, 1959) was used where appropriate. When significant main effects of subject group were found, these were followed by group contrasts (EOS vs. LOS, EOS vs. NC, LOS vs. NC). One-way ANOVAs (or $t$-tests when only two subject groups were applicable) were used for between-group comparisons on demographic and clinical variables, where appropriate.

To investigate the relationship between our mean ERP measures and clinical status, Pearson correlation coefficients were calculated for the P300 peak amplitudes and latencies with various demographic and clinical variables (age, education, age of onset and duration of illness), psychopathology rating scale (BPRS, SAPS, SANS) scores, and global cognitive functioning (MMSE score). For daily neuroleptic dosage [in milligrams chlorpromazine equivalent or CPZE (Jeste and Wyatt, 1982)], the data were non-normally distributed with significant skew. Therefore nonparametric statistical analyses [Mann-Whitney $U$-test for intergroup comparisons and Spearman rho ( $\rho$ ) for correlations] were applied to this variable. For age and education, correlations were computed across all participants $(n=42)$. For age of onset, duration of illness, BPRS, SAPS, SANS and MMSE scores, and neuroleptic dose, correlations were restricted to the two patient groups (EOS and LOS, $n=28$ ). All the statistical tests were two-tailed. All reported measures of variance are standard deviations.

\section{Results}

\subsection{Demographic and clinical variables}

The demographic characteristics of the subject groups are shown in Table 1. There were no significant intergroup differences in age, education, gender, or handedness. There was a significant intergroup difference on the MMSE score $\left(F_{2,39}=5.30 ; \quad P=0.009\right)$, with group contrasts (Duncan test with overall significance level $=0.05$ ) showing the EOS group was significantly different from either the LOS or the NC group. There was no significant difference between the EOS and LOS groups in daily neuroleptic dose (Mann-Whitney $U$-test $=1.67, P=0.10$ ) or psy- 
chopathology rating scale (BPRS: $t_{26}=0.25, P=$ 0.80 ; SAPS: $t_{26}=1.12, P=0.27$; SANS: $t_{26}=0.52$, $P=0.61)$ scores. There also were no significant differences between EOS and LOS on any of the SANS subscale scores (i.e. alogia, avolition, attention, blunted affect and apathy/anhedonia), although there were perhaps tendencies for poorer attention and alogia subscores in EOS than in LOS (Table 1).

\subsection{Behavioral performance on auditory oddball task}

The mean reaction time in response to target tones was $455 \pm 86 \mathrm{~ms}$ for the NC group, $471 \pm 88$ for EOS and $467 \pm 71$ for LOS; these were not significantly different $\left(F_{2,39}=0.14 ; \quad P=0.87\right)$. There also was no significant intergroup difference in the percentage of targets correctly detected. The NC group had $97.5 \pm 4.5 \%$ accuracy vs. $94.2 \pm 6.7 \%$ for EOS and $96.5 \pm 4.5 \%$ for LOS $\left(F_{2,39}=1.42 ; P=0.25\right)$.

\subsection{N100 and N200}

Visual inspection of the grand average waveforms (see Fig. 1) shows that the N100 amplitude was largest over the vertex and anterior scalp regions for all three groups. While there was some tendency for smaller N100 and N200 potentials in the patient groups (i.e. EOS and LOS; see Table 2 and Fig. 1), two-way ANOVA of the N100 amplitude to target tones, with all three groups and all scalp channels as factors, showed a significant main effect of electrode $\left(F_{14,28}=60.5\right.$; $P<0.00005)$ but no main effect of group $\left(F_{2,39}=\right.$ $1.00 ; P=0.38$ ).

An analogous (i.e. target tones) two-way ANOVA of the N100 peak latency showed a main effect of electrode $\left(F_{14,28}=3.56 ; P=0.002\right)$, with a trend for a group effect $\left(F_{2,39}=2.99 ; P=0.06\right)$, with $\mathrm{NC}$ being earliest and EOS latest. There was no significant group $\times$ electrode site interaction for either the N100 amplitude $\left(F_{28,546}=0.88, \varepsilon=\right.$ $0.25 ; P=0.53)$ or latency $\left(F_{28,546}=0.57, \varepsilon=0.43\right.$; $P=0.86)$.

The analysis of the N200 amplitude showed a significant effect of electrode $\left(F_{14,28}=4.00 ; P=\right.$
$0.009)$ but no group effect $\left(F_{2,39}=2.03 ; P=0.14\right)$ nor any interaction effect $\left(F_{28,546}=0.85, \varepsilon=0.22\right.$; $P=0.53)$. An analysis of the N200 amplitude at $\mathrm{Cz}$ (where the N200 amplitude was largest in normal subjects) also failed to show a significant group effect $\left(F_{2,39}=2.49 ; P=0.096\right)$. The N200 latency analysis also showed a significant effect of electrode site $\left(F_{14,28}=10.52 ; P<0.00005\right)$. While the mean peak latency was earliest in $\mathrm{NC}$ and latest in EOS (see Table 2), there was no significant main effect of group $\left(F_{2,39}=2.65 ; P=0.08\right)$ or group $\times$ electrode interaction $\left(F_{28,546}=0.99\right.$, $\varepsilon=0.41 ; P=0.46)$.

\section{4. $P 300$}

The grand average ERP data for the target tones are shown in Fig. 1. Visual inspection of these waveforms shows that the P300 amplitude was smallest in the EOS group, and remarkably normal in the LOS group, who did show a somewhat more prolonged late positivity. All three groups had P300 peak latencies slightly before $400 \mathrm{~ms}$, as might be predicted in this older cohort.

A two-way ANOVA of the P300 mean amplitude, with all three groups and all 15 scalp channels as factors, showed significant main effects of group $\left(F_{2,39}=4.18 ; \quad P=0.02\right)$ and electrode $\left(F_{14,28}=18.8 ; \quad P<0.0001\right)$. Group contrasts showed the P300 amplitude was significantly reduced in the EOS patients (by approx. 55\%), relative to the $\operatorname{LOS}(P=0.03)$ and to the NC group $(P=0.02)$. There was no significant group $\times$ electrode interaction effect $\left(F_{28,546}=0.95, \varepsilon=\right.$ $0.25 ; P=0.54$ ).

An analogous two-way ANOVA of the P300 peak amplitude also showed significant main effects of group $\left(F_{2,39}=4.36 ; P=0.02\right)$ and electrode $\left(F_{14,28}=20.8 ; P<0.0001\right)$. P300 peak amplitude was smallest in the EOS group, and the group contrasts showed this reduction to be significant relative to both the LOS $(P=0.02)$ and NC groups $(P=0.02)$. Single electrode analyses showed significant main effects of group at $\mathrm{Cz}$, Pz, L41, T5 and WL (see Fig. 2). The group effect also narrowly missed statistical significance $(0.05$ $<P<0.10)$ at five other sites (Fz, R41, T6, WR and $\mathrm{O} 1)$. 
NC

FRONTAL (FZ)

CENTRAL (Cz)

PARIETAL (Pz)

L. FRONTAL

R. FRONTAL

L. BROCAS

R. BROCAS

L. AREA 41

R. AREA 41

L. WERNICKES

R. WERNICKES

L. POSTERIOR TEMPORAL

R. POSTERIOR TEMPORAL

L. OCCIPITAL

R. OCCIPITAL
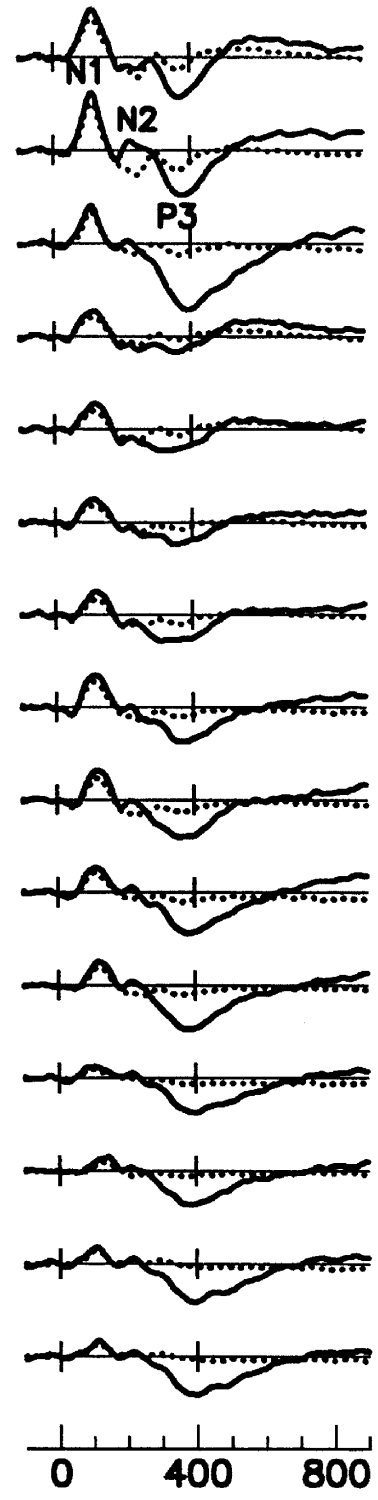

Targets
EOS
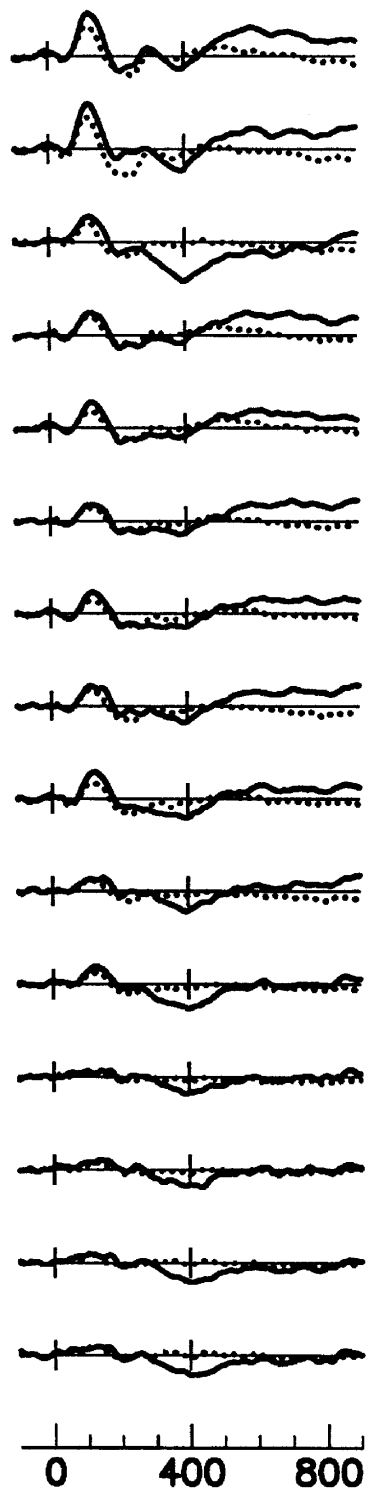

LOS
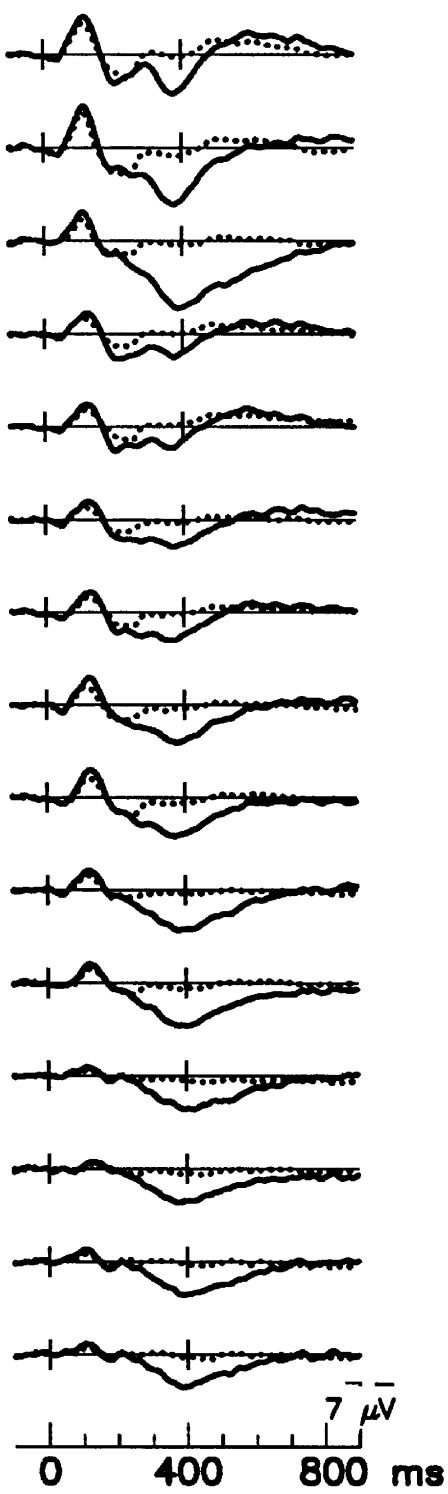

\section{Standards}

Fig. 1. Grand average waveforms for the three subject groups: normal comparison (NC), early onset schizophrenia (EOS) and late onset schizophrenia (LOS). The N100 (N1), N200 (N2) and P300 (P3) potentials are illustrated on the tracing for the central (Cz) channel of the NC group. Negative is plotted up, positive down.

The topographical distributions of the P300 peak amplitude for the three subject groups are illustrated in Fig. 2. Additional topographical analyses of the P300 peak amplitude at the 12 
Table 2

Summary of ERP data

\begin{tabular}{lccc}
\hline & NC & EOS & LOS \\
\hline $\begin{array}{l}\text { P300 mean ampli- } \\
\text { tude }(\mu \mathrm{V})^{*}\end{array}$ & $3.3(2.4)$ & $1.5(2.8)$ & $3.5(3.0)$ \\
$\begin{array}{c}\text { P300 peak ampli- } \\
\text { tude }(\mu \mathrm{V})^{*}\end{array}$ & $4.4(2.4)$ & $2.7(2.7)$ & $4.9(3.2)$ \\
P300 latency (ms) & $381(40)$ & $394(60)$ & $391(62)$ \\
N200 amplitude & $-0.6(2.0)$ & $-0.6(2.0)$ & $+0.4(2.4)$ \\
N200 latency & $239(31)$ & $256(35)$ & $245(36)$ \\
N100 amplitude & $-3.3(1.8)$ & $-2.8(1.9)$ & $-2.7(1.8)$ \\
N100 latency & $119(16)$ & $127(21)$ & $122(16)$
\end{tabular}

${ }^{*} P<0.05 ;$ ANOVA group effect.

Notes. The values represent means (with S.D.). P300, N200 and N100 - measured across all 15 scalp channels.

Abbreviations. ERP, event-related potential; NC, normal comparison group; EOS, early onset schizophrenia; LOS, late onset schizophrenia.

lateral scalp channels were performed, using split-plot ANOVA with group (a between-subject factor), hemisphere and electrode site (withinsubject factors) as factors. This showed significant effects of group $\left(F_{2,39}=4.24 ; P=0.02\right)$ and electrode $\left(F_{5,10}=15.53 ; P<0.0001\right)$, but no main effect of hemisphere $\left(F_{1,2}=1.36 ; P=0.25\right)$ nor any significant interaction effects (e.g. $P=0.64$ for group $\times$ hemisphere and $P=0.73$ for group $\times$ electrode). The group contrasts showed the EOS group was significantly different from the LOS and the NC group $(P=0.02)$. The highly significant electrode effect was due to the much larger $\mathrm{P} 300$ s over posterior compared to anterior head

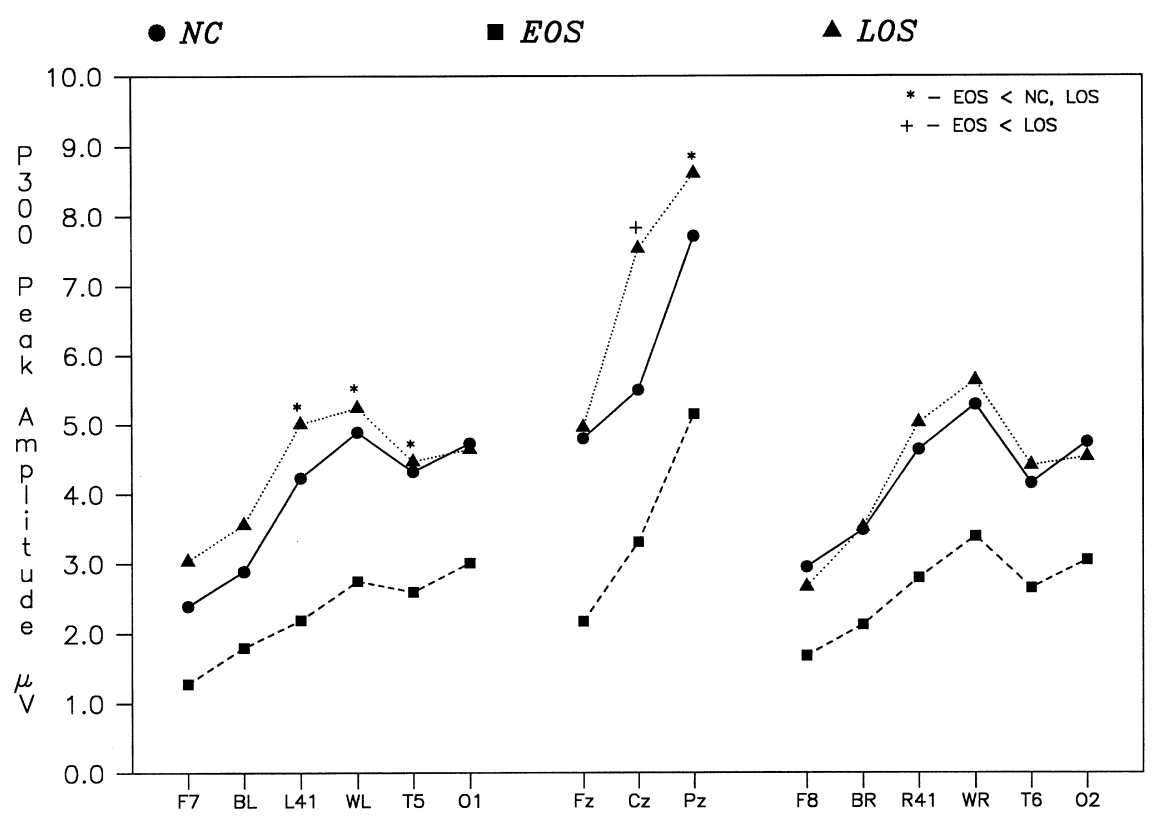

Fig. 2. Peak P300 amplitudes displayed for the left hemisphere (on the left), midline (center), and right hemisphere (on the right) electrode sites. Mean values are represented as squares ( $\mathbf{a})$ for the early onset schizophrenia group (EOS), as triangles ( $\boldsymbol{\Delta}$ ) for the late onset schizophrenia group (LOS), and circles (•) for the normal comparison group (NC). 
regions. An analogous ANOVA was performed across the three midline channels $(\mathrm{Fz}, \mathrm{Cz}, \mathrm{Pz})$ and essentially the same results were found: significant effects of group and electrode, but no interaction effect.

An ANOVA of the P300 peak latency showed no significant effect of group $\left(F_{2,39}=0.54 ; P=\right.$ $0.58)$ nor any group $\times$ electrode interaction $\left(F_{28,546}=0.53, \varepsilon=0.32 ; P=0.85\right)$. See Table 2 for a summary of the mean P300 measures for each group.

\subsection{Individual subject ERPs}

The individual subject waveforms (at $\mathrm{Pz}$, the parietal midline site) and clinical diagnoses are shown in Fig. 3. The NC group had a range of P300 amplitudes (at Pz) between 3.02 and 13.04 $\mu \mathrm{V}$ (mean \pm S.D. $=7.72 \pm 2.98)$ and a range of P300 latencies of 340-416 ms (mean \pm S.D. $=392$ $\pm 26)$. P300 values which were $>1.5$ S.D. poorer than the mean of the $\mathrm{NC}$ group were classified as 'abnormal'. Six patients (four EOS and two LOS) and one NC subject showed abnormally small P300 amplitudes (i.e. $<3.28 \mu \mathrm{V}$ ). An abnormal P300 latency (i.e. any value later than $431 \mathrm{~ms}$ ) was found in 10 patients (five EOS and five LOS) and one NC subject.

\subsection{P300 / clinical correlations}

Correlational analyses in the patient groups (EOS and LOS; $n=28$ ) showed that the peak amplitude of the P300 was significantly correlated with age of onset $(r=0.48, P=0.01)$ and duration of illness $(r=-0.49, P=0.009)$, wherein smaller amplitudes were associated with an earlier onset and a longer duration of illness (see Fig. 4). Follow-up correlational analyses of P300 amplitude examined each of the patient groups (EOS and LOS) separately. Within the EOS group, the age of onset correlation was of similar magnitude as in the combined analysis $(r=0.47)$, but was only marginally significant $(P=0.09)$, and the duration of illness correlation became smaller $(r=-0.38)$ and non-significant $(P=0.18)$. Within LOS, neither age of onset $(r=0.06)$ nor duration of illness $(r=-0.17)$ correlated with P300 amplitude.

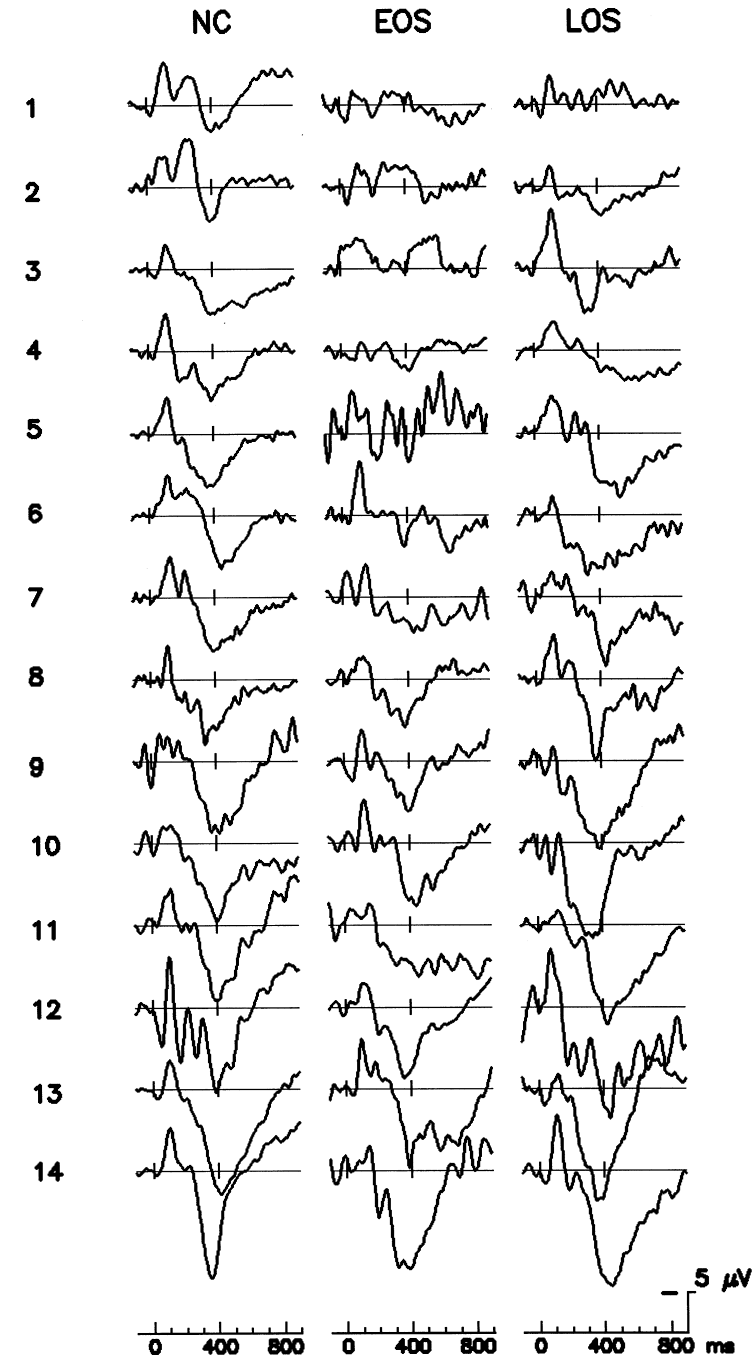

Fig. 3. Individual subject ERP data at $\mathrm{Pz}$ electrode for all subjects. NC, normal comparison group; EOS, early onset schizophrenia; LOS, late onset schizophrenia. The three subjects with schizoaffective disorder are shown as LOS 2 (small P300 amplitude), LOS 13 (large P300) and EOS 10 (large P300).

The P300 peak amplitude showed no significant correlation with BPRS score $(r=-0.17)$, SAPS score $(r=-0.06)$, daily neuroleptic dosage (Spearman's $\rho=-0.02)$ or MMSE score $(r=$ 0.21 ). Peak amplitudes showed no significant correlation with the overall severity of negative symptoms $(r=-0.21$ with total SANS score, $P=$ 0.29). However, correlations of the P300 peak 
amplitude with the SANS subscale scores (attention, alogia, avolition/apathy, affective flattening, and anhedonia/asociality) showed that the Alogia subscale score correlated well $(r=-0.50$, $P=0.007)$ with reduced P300 amplitudes. Also, the correlations with both the Affective flattening $(r=-0.33, P=0.088)$ and Attention subscale scores approached significance $(r=-0.35, P=$ 0.071). The Attention subscale correlation reached statistical significance once the NC group was included $(r=-0.36, P=0.02)$. The P300 peak latency did not correlate significantly with any of the clinical variables studied, but modest non-significant correlations were noted for duration of illness $(r=0.34, P=0.08)$ and daily neuroleptic dosage $(\rho=0.30, P=0.12)$. Across all subjects $(n=42)$, there was no significant correlation of the peak amplitude or peak latency with age ( $r=-0.04$ and $r=0.15$, respectively) or education $(r=-0.02, P=0.92$, and $r=-0.26, P=$ 0.09 , respectively).

\section{Discussion}

To our knowledge, the present study is the first to report on the P300 in LOS. In contrast to the considerable research devoted to the P300 in younger schizophrenia cohorts, very little work has been published on this brain potential in older schizophrenia patients. Consistent with the literature on the P300 in younger patients with schizophrenia, we also found reduced P300 amplitudes (approx. 55\% reduction in mean amplitude and $40 \%$ reduction in peak amplitude) in middle-aged and elderly EOS patients. In contrast, our older patients with late onset were characterized by normal P300 amplitudes. This is an intriguing finding worthy of subsequent investigation. Furthermore, correlational analyses revealed a significant relationship between the amplitude of the auditory P300 and the age of onset of illness. Earlier onset was associated with smaller P300s. Likewise, longer duration of disease was associated with smaller P300s. Because the P300s of our EOS patients closely resembled those described in young adult schizophrenia patients (Roth et al., 1981; Blackwood et al., 1987; Ford et al., 1992), we doubt that this correlation is due to a significant longitudinal decline of their P300 amplitudes (although an increased rate of P300 latency prolongation with age has been inferred in a recent cross-sectional study of men with chronic schizophrenia) (O'Donnell et al., 1995).

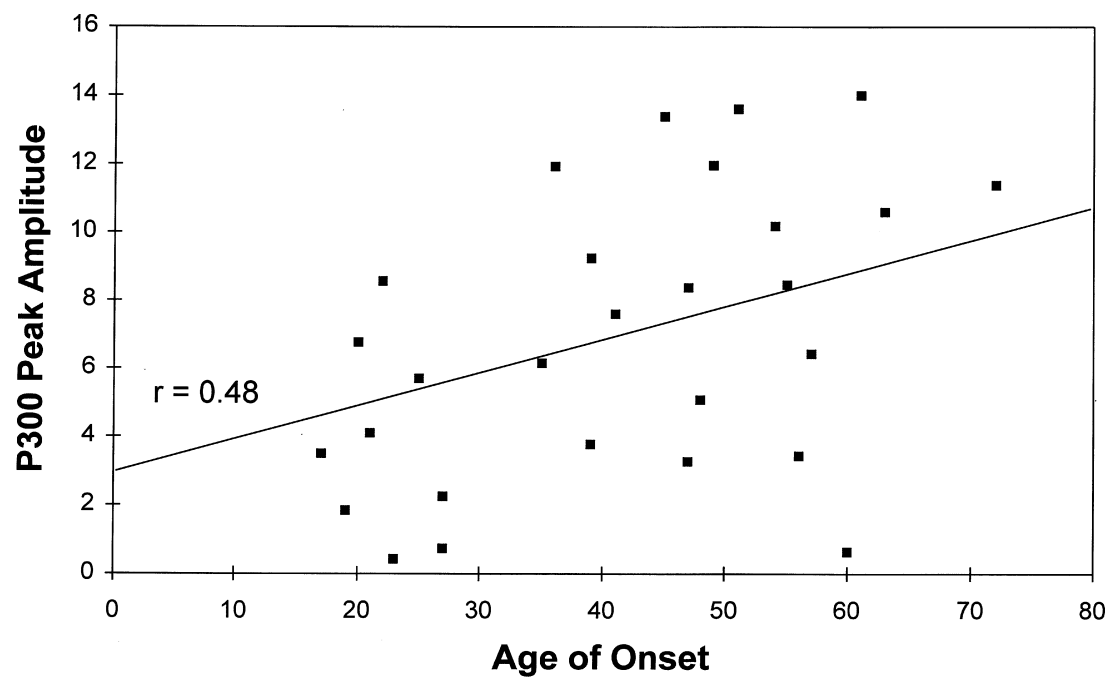

Fig. 4. Scatterplot of P300 peak amplitude (at Pz, mid-parietal site) with age of onset for all early onset schizophrenia (EOS) and late onset schizophrenia (LOS) subjects. 
It is intriguing to consider when during neurodevelopment EOS patients first display attenuated P300 amplitudes. Prior studies have found reduced amplitudes in schizophrenic children (Erwin et al., 1986). In children at high risk for schizophrenia, delayed P300 latencies (Schreiber et al., 1989) but relatively normal P300 amplitudes have been described (Friedman et al., 1988). Only a minority of these children are likely to develop schizophrenia, however, and the predictive value of $\mathrm{P} 300$ abnormalities in individuals at high risk remains unknown.

Studies of the P300 in normal children have generally shown P300 latency to decrease and P300 amplitude to increase with age during development. Most, but not all, published data suggest that P300 amplitude increases in a fairly linear manner over the course of childhood (Martin et al., 1988; Polich et al., 1990). The P300's characteristic sensitivity to target stimulus probability appears to be well established in most children between 5 and 9 years old (Ladish and Polich, 1989). Most studies of adults have found that auditory P300 amplitude declines modestly with age from the third decade on. This rate has been estimated to be $-0.1 \mu \mathrm{V} /$ year in our laboratory (Iragui et al., 1993) and somewhat steeper $(-0.18$ $\mu \mathrm{V} /$ year) by others (Picton et al., 1984).

At the clinical level of description, it may be that the spared P300 amplitudes of our LOS patients are related to their milder impairment in learning/acquisition and attention relative to older patients with early onset (Heaton et al., 1994; Jeste et al., 1997). This is in line with substantial literature which has related the P300 to working memory 'updating' or working memory load (e.g. Donchin et al., 1986). Exploratory analyses showed an inverse correlation between P300 amplitude and the Attention subscale score on the SANS, consistent with this hypothesis. Alternatively, considering that LOS patients have somewhat less severe cognitive deficits globally compared to EOS, it is possible that the observed intergroup differences in P300 are due to cognitive domains other than attention or learning/acquisition. However, the P300 amplitude did not correlate with global cognition, as measured by the Mini-Mental State Exam, in our cohort. Another clinical variable which did correlate with P300 amplitude reductions was severity of alogia. While this association has been reported previously (Ward et al., 1991), other investigators (Stefánsson and Jónsdóttir, 1996) have found no correlation between alogia severity and the P300 amplitude in schizophrenia. As this correlation was not hypothesized a priori and previous results are mixed, it needs to be replicated in independent samples. When we compared the SANS alogia subscale scores of the EOS and LOS groups, there was no significant difference. Therefore it is unlikely that the observed correlation between the P300 and age of onset of schizophrenia is a spurious one, due to alogia. Further work is needed to better define the neuropsychological deficits of schizophrenia patients with vs. without P300 abnormalities.

It should be noted that the presence of normal auditory P300 amplitudes in LOS cannot be taken as evidence of completely 'normal' information processing abilities in these patients. For example, several of these same individuals showed significantly delayed N400s in a semantic categorization task (Olichney et al., 1997). A more demanding auditory categorization task may well have shown greater sensitivity to the mild cognitive deficits seen in LOS.

Multiple brain structures generate P300-like potentials, including the hippocampus, parahippocampal gyrus, temporoparietal junction, thalamus and frontal cortex (Knight et al., 1989; McCarthy et al., 1989; Smith et al., 1990; Kropotov and Ponomatrev, 1991). Microscopic abnormalities of the hippocampus, including disorganized neuronal architecture and reduced neuron size, have frequently been observed in schizophrenia (Kovelman and Scheibel, 1984; Jeste and Lohr, 1989; Conrad et al., 1991). There is compelling evidence from intracranial recordings that the hippocampus is a $\mathrm{P} 300$ generator, but its direct contributions to the scalp-recorded P300 in oddball tasks are modest (McCarthy et al., 1989; Smith et al., 1990; Polich and Squire, 1993). As scalp ERPs reflect spatially summated excitatory and inhibitory post-synaptic potentials (EPSPs and IPSPs), the P300 abnormalities in schizophrenia could be a sign of disturbed neuronal migration 
during brain development. Alternatively, abnormal P300s may be secondary to macroscopic abnormalities of the hippocampus, such as have been revealed by some neuroimaging studies (Suddath et al., 1990; Shenton et al., 1992; Bogerts et al., 1993), or other brain structures related to attention and working memory. McCarley et al. (1993) have reported that reductions of the left posterior superior temporal gyrus gray matter volume, a structure considered important for auditory associative memory (Ojemann et al., 1988), are associated with smaller and more asymmetric (left < right) P300s. While we did not find significantly asymmetric P300s in our EOS or LOS groups, single electrode analyses showed reduced P300 amplitudes in EOS at all three left temporal recording sites, supporting greater involvement of the dominant temporal lobe in EOS.

A quantitative MRI study conducted at our center found reduced thalamic volumes in EOS relative to LOS (Corey-Bloom et al., 1995). Thus, one possibility is that spared thalamic function and relatively normal processing of sensory information may be a protective factor in LOS, perhaps resulting in normal P300 amplitudes and later disease onset. Depth recordings have demonstrated P300-like activity in the ventrallateral (Kropotov and Ponomatrev, 1991) and medial geniculate thalamic nuclei (Velasco et al., 1989). Neurosurgical patients with prolonged P300s have been reported to often have reduced regional blood flow in the right thalamus and right frontal lobe (Kuwata et al., 1993).

We did not find significant abnormalities of the ERPs prior to the P300 (i.e. either the N100 or N200) in our schizophrenia patients (EOS or LOS). This could, however, be due to Type II error with our limited sample size. Specifically, the non-significant trends towards slower N100 and N200 latencies in EOS could prove to be significant with larger samples.

In summary, we found the auditory P300 amplitude to be related to age of onset of illness in a cohort of older schizophrenia patients. Smaller P300s were seen in older EOS than in LOS patients of comparable age and global psychopathology. The neurobiological underpinnings of this finding remain unclear. Among the many possible explanations (which are not mutually exclusive) are that reduced P300 amplitudes are causally related to: (i) poorer attention and information processing; (ii) specific microscopic or macroscopic abnormalities of the P300 generators; (iii) diffuse impairment of synaptic transmission, perhaps involving multiple neurotransmitter systems; and (iv) more severe neurodevelopmental abnormalities in EOS than LOS. It may be that reduced P300 amplitudes are related to a disease subtype characterized by earlier onset, poorer information processing, and perhaps more severe neurodevelopmental abnormalities (Crow, 1980; Murray et al., 1988). Further studies are needed to rigorously test and develop these hypotheses and to test to what extent EOS and LOS are distinct disease subtypes.

\section{Acknowledgements}

This work was supported, in part, by National Institute of Mental Health grants MH49671 and MH43693, National Institute on Aging grant AG08313, a NARSAD Young Investigator Award, The Stein Institute of Research on Aging, and the Department of Veterans Affairs.

\section{References}

American Electroencephalographic Society 1991. Guidelines for standard electrode position nomenclature. Journal of Clinical Neurophysiology 8, 200-202.

American Psychiatric Association, 1987. Diagnostic and Statistical Manual of Mental Disorders, 3rd ed, revised. American Psychiatric Press, Washington, DC.

Anderson, J., Gordon, E., Barry, R.J., Rennie, C., Beumont, P.J., Meares, R., 1995. Maximum variance of late-component event related potentials (190-240 ms) in unmedicated schizophrenic patients. Psychiatry Research 56, 229-236.

Andreasen, N.C., 1982. Negative symptoms in schizophrenia: definition and reliability. Archives of General Psychiatry 39, 784-788.

Andreasen, N.C., 1984. The Scale for the Assessment of Positive Symptoms (SAPS). The University of Iowa, Iowa City.

Andreasen, N.C., Olsen, S., 1982. Negative vs. positive schizophrenia: definition and validation. Archives of General Psychiatry 39, 789-794.

Baribeau-Braun, J., Picton, T.W., Gosselin, J., 1983. Schizophrenia: a neuropsychological evaluation of abnormal information processing. Science $219,874-876$. 
Blackwood, D., Whalley, L., Christie, J., Blackburn, I.M., St Clair, D.M., McInnes, A., 1987. Changes in auditory P3 event-related potential in schizophrenia and depression. British Journal of Psychiatry 150, 154-160.

Blackwood, D.H.R., St Clair, D.M., Muir, W.J., Duffy, J.C., 1991. Auditory P300 and eye tracking dysfunction in schizophrenia pedigrees. Archives of General Psychiatry 48, 899-909.

Bogerts, B., Lieberman, J.A., Ashtari, M., Bilder, R.M., Degreef, G., Lerner, G., Johns, C., Masiar, S., 1993. Hippocampus-amygdala volumes and psychopathology in chronic schizophrenia. Biological Psychiatry 33, 236-243.

Chua, S.E., McKenna, P.J., 1995. Schizophrenia - a brain disease? British Journal of Psychiatry 166, 563-582.

Conrad, A., Abebe, T., Austin, R., Forsythe, S., Scheibel, A.B., 1991. Hippocampal pyramidal cell disarray in schizophrenia as a bilateral phenomenon. Archives of General Psychiatry 40, 413-417.

Corey-Bloom, J., Jernigan, T., Archibald, S., Harris, M.J., Jeste, D.V., 1995. Quantitative magnetic resonance imaging in late-life schizophrenia. American Journal of Psychiatry 152, 447-449.

Crow, T.J., 1980. Molecular pathology of schizophrenia: more than one disease process? British Medical Journal 280, 66-68.

Donchin, E., Karis, D., Bashore, T., Coles, M.G.H., Gratton, G., 1986. Cognitive psychophysiology and human information processing. In: Coles, M.G.H., Donchin, E., Porges, S.W. (Eds.), Psychophysiology: Systems, Processes and Applications. Guilford Press, New York, pp. 244-267.

Donchin, E., Coles, M.G.H., 1988. Precommentary on Verleger's critique of the context updating model. Brain Behavioral Studies 11, 357-373.

Duncan, C.C., Morihisa, J.M., Fawcet, R.W., Kirch, D.G., 1987. P300 in schizophrenia: state or trait marker? Psychopharmacology Bulletin 23, 497-501.

Duncan-Johnson, C.C., Donchin, E., 1977. On quantifying surprise: the variation of event-related potentials with subjective probability. Psychophysiology 14, 456-467.

Egan, M.F., Duncan, C.C., Suddath, R.L., Kirch, D.G., Mirsky, A.F., Wyatt, R.J., 1994. Event-related potential abnormalities correlate with structural brain alterations and clinical features in patients with chronic schizophrenia. Schizophrenia Research 11, 259-271.

Erwin, R.J., Edwards, R., Tanguay, P.E., Buchwald, J., Letai, D., 1986. Abnormal P300 responses in schizophrenic children. Journal of the American Academy of Child and Adolescent Psychiatry 25, 615-622.

Folstein, M.F., Folstein, S.E., McHugh, P.R., 1975. MiniMental State: a practical method for grading the cognitive state of patients for the clinician. Journal of Psychiatric Research 12, 189-198.

Ford, J., Roth, W., Pfefferbaum, A., 1992. P3 and schizophrenia. In: Friedman, D., Bruder, G. (Eds.), Psychophysiology and Experimental Psychopathology: A Tribute to Samuel Sutton. New York Academy of Sciences, New York, pp. $146-162$
Ford, J.M., White, P.M., Csernansky, J.G., Faustman, W.O., Roth, W.T., Pfefferbaum, A., 1994. ERPs in schizophrenia: effects of antipsychotic medication. Biological Psychiatry 36, 153-170.

Frangou, S., Sharma, T., Alarcon, G., Sigmudsson, T., Takei, N., Binnie, C., Murray, R.M., 1997. The Maudsley Family study, II: endogenous event-related potentials in familial schizophrenia. Schizophrenia Research 23, 45-53.

Friedman, D., Cornblatt, B., Vaughan, H., ErlenmeyerKimling, L., 1988. Auditory event-related potentials in children at risk for schizophrenia: the complete initial sample. Psychiatry Research 26, 203-221.

Greenhouse, S.W., Geisser, S., 1959. On methods in the analysis of profile data. Psychometrika 24, 95-112.

Harris, M.J., Jeste, D.V., 1988. Late-onset schizophrenia: an overview. Schizophrenia Bulletin 14, 39-55.

Heaton, R., Paulsen, J., McAdams, L.A., Kuck, J., Zisook, S., Braff, D., Harris, M.J., Jeste, D.V., 1994. Neuropsychological deficits in schizophrenia: relationship to age, chronicity and dementia. Archives of General Psychiatry 51, 469-476.

Iragui, V.J., Kutas, M., Mitchiner, M., Hillyard, S.A., 1993. Effects of aging on event-related brain potentials in an auditory oddball task. Psychophysiology 30, 10-22.

Isreal, J.B., Chesney, G.L., Wickens, C.D., Donchin, E., 1980. P300 and tracking difficulty: evidence for multiple resources in dual performance. Psychophysiology 17, 57-70.

Jasper, H.H., 1958. Report to the committee on methods of clinical examination in electroencephalography. Appendix: the ten-twenty system of the International Federation. Electroencephalography and Clinical Neurophysiology 10, 371-375

Jeste, D.V., Harris, M.J., Krull, A., Kuck, J., McAdams, L.A., Heaton, R., 1995. Clinical and neuropsychological characteristics of patients with late-onset schizophrenia. American Journal of Psychiatry 152, 722-730.

Jeste, D.V., Lohr, J.B., 1989. Hippocampal pathologic findings in schizophrenia: a morphometric study. Archives of General Psychiatry 46, 1019-1024.

Jeste, D.V., Symonds, L.L., Harris, M.J., Paulsen, J.S., Palmer, B.W., Heaton, R.K., 1997. Non-dementia non-praecox dementia praecox? late-onset schizophrenia. American Journal of Geriatric Psychiatry 5, 302-317.

Jeste, D.V., Wyatt, R.J., 1982. Understanding and Treating Tardive Dyskinesia. Guilford Press, New York.

Johnson, R., Jr., 1988. The amplitude of the P300 component of the event-related potential: review and synthesis. In: Ackles, P.K., Jennings, J.R., Cole, M.G.H. (Eds), Advances in Psychophysiology, vol. III. J.A.I. Press, Connecticut, pp. 69-137.

Kidogami, Y., Yoneda, H., Asaba, H., Sakai, T., 1992. P300 in first degree relatives of schizophrenics. Schizophrenia Research 6, 9-13.

Knight, R.T., Scabini, D., Woods, D.L., Clayworth, C., 1989. Contributions of the temporal-parietal junction to the human auditory P3. Brain Research 13, 109-116.

Kovelman, J., Scheibel, A., 1984. A neurohistological correlate of schizophrenia. Biological Psychiatry 19, 1601-1621. 
Kramer, A.F., Wickens, C.D., Donchin, E., 1983. An analysis of the processing requirements of a complex perceptualmotor task. Human Factors 25, 597-622.

Kropotov, J.D., Ponomatrev, V.A., 1991. Subcortical neuronal correlates of component P300 in man. Electroencephalography and Clinical Neurophysiology 78, 40-49.

Kuwata, T., Funahashi, K., Maeshima, S., Ogura, M., Hyotani, G., Terada, T., Itakura, T., Hayashi, S., Komai, N., 1993. Influence of regional cerebral blood flow on event-related potential (P300). Neurologia Medico-Chirurgica 33, 146-151.

Ladish, C., Polich, J., 1989. P300 and probability in children. Journal of Experimental Child Psychology 48, 212-223.

Martin, L., Barajas, J.J., Fernandez, R., Torres, E., 1988. Auditory event-related potentials in well-characterized groups of children. Electroencephalography and Clinical Neurophysiology 71, 375-381.

McCarley, R.W., Shenton, M.E., O'Donnell, B.F., Faux, S.F., Kikinis, R., Nestor, P.G., Jolesz, F.A., 1993. Auditory P300 abnormalities and left posterior superior temporal gyrus volume reduction in schizophrenia. Archives of General Psychiatry 50, 190-197.

McCarthy, G., Wood, C.C., Williamson, P.D., Spencer, D.D., 1989. Task-dependent field potentials in human hippocampal formation. Journal of Neuroscience 9, 4253-4268.

Murray, R.M., Lewis, S.W., Owen, M.J., Foerster, A., 1988. The neurodevelopmental origins of dementia praecox. In: Bebbington, P., McGuffin, P. (Eds.), Schizophrenia: The Major Issues. William Heinemann, London, pp. 90-107.

Murray, R.M., O'Callaghan, E., Castle, D.J., Lewis, S.W., 1992. A neurodevelopmental approach to the classification of schizophrenia. Schizophrenia Bulletin 18, 319-332.

O’Donnell, B.F., Faux, S.F., McCarley, R.W., Kimble, M.O., Salisbury, D.F., Nestor, P.G., Kikinis, R., Jolesz, F.A., Shenton, M.E., 1995. Increased rate of P300 latency prolongation with age in schizophrenia. Archives of General Psychiatry $52,544-549$.

Ojemann, G.A., Creutzieldt, O., Lettich, E., Haglund, M., 1988. Neuronal activity in human lateral temporal cortex related to short-term verbal memory, naming and reading. Brain 111, 1383-1403.

Olichney, J.M., Iragui, V.J., Kutas, M., Nowacki, R., Jeste, D.V., 1997. N400 abnormalities in late-life schizophrenia and related psychoses. Biological Psychiatry 42, 13-23.

Overall, J.E., Gorham, D.R., 1962. The Brief Psychiatric Rating Scale. Psychological Reports 10, 799-812.

Paulsen, J.S., Heaton, R.K., Sadek, J.R., Perry, W., Delis, D.C., Braff, D., Kuck, J., Zisook, S., Jeste, D.V., 1995. The nature of learning and memory impairments in schizophrenia. Journal of the International Neuropsychological Society $1,88-99$.

Pfefferbaum, A., Ford, J.M., White, P.M., Roth, W.T., 1989. P3 in schizophrenia is affected by stimulus modality, response requirements, medication status, and negative symptoms. Archives of General Psychiatry 46, 1035-1044.

Picton, T.W., Stuss, D.T., Champagne, S.C., Nelson, R.F.,
1984. The effects of age on human event-related potentials. Psychophysiology 21, 312-325.

Polich, J., Ladish, C., Burns, T., 1990. Normal variation of P300 in children: age, memory span, and head size. International Journal of Psychophysiology 9, 237-248.

Polich, J., Squire, L., 1993. P300 from amnesic patients with bilateral hippocampal lesions. Electroencephalography and Clinical Neurophysiology 86, 408-417.

Roth, W.T., Pfefferbaum, A., Kelly, A.F., Berger, P.A., Kopell, B.S., 1981. Auditory event related potentials in schizophrenia and depression. Psychiatry Research 4, 199-212.

Schreiber, H., Stolz, G., Rothmeier, J., Kornhuber, H.H., Born, J., 1989. Prolonged latencies of the N2 and P3 of the auditory event-related potential in children at risk for schizophrenia. European Archives of Psychiatry and Neurological Sciences 238, 185-188.

Shenton, M.E., Kikinis, R., Jolesz, F.A., Pollak, S.D., LeMay, M., Wible, C., Hokama, H., Martin, J., Metcalf, D., Coleman, M., McCarley, R.W., 1992. Abnormalities of the left temporal lobe and thought disorder in schizophrenia: a quantitative magnetic resonance imaging study. New England Journal of Medicine 327, 604-612.

Smith, M.E., Halgren, E., Sokolik, M., Baudena, P., Musolino, A., Liegeois-Chauvel, C., Chauvel, P., 1990. The intracranial topography of the $\mathrm{P} 3$ event-related potential elicited during auditory oddball. Electroencephalography and Clinical Neurophysiology 76, 235-248.

Spitzer, R.L., Williams, J.B.W., Gibbon, M., First, M.B., 1988. Structured Clinical Interview for DSM-III-R - Patient Version (SCID-P, 4/1/88). Biometrics Research Department, New York State Psychiatric Institute, New York.

Stefánsson, S.B., Jónsdóttir, T.J., 1996. Auditory event-related potentials, auditory digit span, and clinical symptoms in chronic schizophrenic men on neuroleptic medication. Biological Psychiatry 40, 19-27.

Strik, W.K., Dierks, T., Maurer, K., 1993. Amplitudes of auditory P300 in remitted and residual schizophrenics: correlations with clinical features. Neuropsychobiology 27, $54-60$.

Suddath, R.L., Christison, G.W., Torrey, E.F., Casanova, M.F., Weinberger, D.R., 1990. Anatomical abnormalities in the brains of monozygotic twins discordant for schizophrenia. New England Journal of Medicine 322, 789-794.

Trestman, R.L., Horvath, T., Kalus, O., Peterson, A.E., Coccaro, E., Mitropoulou, V., Apter, S., Davidson, M., Siever, L.J., 1996. Event-related potentials in schizotypal personality disorder. Journal of Neuropsychiatry 8, 33-40.

Velasco, M., Velasco, F., Velasco, A.L., 1989. Intracranial studies on potential generators of some vertex auditory evoked potentials in man. Stereotactic and Functional Neurosurgery 53, 49-73.

Ward, P.B., Catts, S.V., Fox, A.M., Michie, P.T., McConaghy, N., 1991. Auditory selective attention and event-related potentials in schizophrenia. British Journal of Psychiatry $158,534-539$. 